\title{
Fast Foods, Emotional and Behavioural Problems among Overweight and Obese Adolescents Participating in MyBFF@school Intervention Program
}

\author{
Zahari Ishak ${ }^{*}$, Low Suet Fin², Wan Abdul Hakim Wan Ibrahim ${ }^{1}$, \\ Abqariyah Yahya ${ }^{3}$, Fuziah Md. Zain ${ }^{4}$, Rusidah Selamat ${ }^{5}$, \\ Muhammad Yazid Jalaludin ${ }^{6}$, and Abdul Halim Mokhtar ${ }^{7}$
}

\begin{abstract}
This study aimed to assess the association between the frequency of fast food consumption in the past week with emotional and behavioural problems of 624 overweight and obese adolescents (mean age $=14.6$ ). Frequency of fast food consumption was assessed through a pre-tested nutritional knowledge, attitude and practice questionnaire. Meanwhile, the Youth Self-Report questionnaire was used to measure emotional and behavioural problems. Spearman's rank-order correlation was used to measure the strength of relationships. Positive associations that are statistically significant were found between frequency of fast food consumption and syndromes of anxious/depressed $\left(\mathrm{r}_{\mathrm{s}}=0.082, \mathrm{p}<0.05\right)$, somatic complaints $\left(r_{s}=0.139, p<0.01\right)$, social problems $\left(r_{s}=0.115, p<0.01\right)$, thought problems $\left(r_{s}=0.118, p<0.01\right)$, attention problems $\left(\mathrm{r}_{\mathrm{s}}=0.125, \mathrm{p}<0.01\right)$, rule-breaking behaviour $\left(\mathrm{r}_{\mathrm{s}}=0.144, \mathrm{p}<0.001\right)$, and aggressive behaviour $\left(r_{s}=0.168, p<0.001\right)$. There were also differences found in the associations based on gender, locality of schools and ethnicity. Therefore, adolescents should be discouraged from consuming fast food as much as possible.
\end{abstract}

\section{Keywords}

adolescents, behavioural problems, emotional problems, fast foods, overweight and obese

\footnotetext{
* Correspondence: irahaz@um.edu.my

${ }^{1}$ Department of Educational Psychology and Counselling, Faculty of Education, University of Malaya, 50603 Kuala Lumpur, Malaysia

${ }^{2}$ Road User Behavioural Change Research Centre, Malaysian Institute of Road Safety Research, ASEAN Road Safety Centre, 43000 Kajang, Malaysia

${ }^{3}$ Department of Social and Preventive Medicine, Faculty of Medicine, University of Malaya, 50603 Kuala Lumpur, Malaysia

${ }^{4}$ Department of Paediatrics, Putrajaya Hospital, Ministry of Health Malaysia, 62250 Putrajaya, Malaysia

${ }^{5}$ Nutrition Division, Ministry of Health Malaysia, 62590, Putrajaya, Malaysia

${ }^{6}$ Department of Paediatrics, Faculty of Medicine, University of Malaya, 59100 Kuala Lumpur, Malaysia

${ }^{7}$ Unit of Sports Medicine, Faculty of Medicine, University of Malaya, 59100 Kuala Lumpur, Malaysia
} 


\section{Introduction}

Fast food contains trans fatty acids that increases the ratio of LDL to HDL cholesterol and the risk of developing coronary heart disease (Brouwer, Wanders, \& Katan, 2010; Mozaffarian, Katan, Ascherio, Stampfer, \& Willett, 2006). The World Health Organisation (WHO) advises reducing trans fatty acid consumption to less than $1 \%$ of total energy intake to lower the risk of non-communicable diseases ("Healthy diet," n.d.). However, there is an increasing trend from 1977 to 2006 in the energy intake from fast foods among the US children (Poti \& Popkin, 2011; Surveys, 1984; U.S. Department of Agriculture ARS BHNRC, Food Surveys Research Group, n.d.). The increasing trend is alarming as popular fast foods bought from twenty countries were found to have a very high amount $(0.4 \%$ to $40 \%)$ of trans fatty acids (Stender, Dyerberg, \& Astrup, 2006). Moreover, a recent study in China found that half of the children participating in their study consumed fast foods in the previous three months and more than $10 \%$ of the children were obese (Zhao, Wang, Xue, Wang, \& Wang, 2017). The fact that fast foods are potentially addictive in nature, couple with how little overweight and obese children have control over their eating behaviour make these children more vulnerable to the detrimental effects of fast foods consumption (K. Garber \& H. Lustig, 2011; Nederkoorn, Braet, Van Eijs, Tanghe, \& Jansen, 2006).

Apart from the effects on the physical health, food consumption could also affect psychological well-being. This warrants a different perspective on understanding the effects of fast food (Carabotti, Scirocco, Maselli, \& Severi, 2015). Animal study found that rats exhibit mania-like behaviour after prolonged consumption of trans fat (Trevizol et al., 2015). Further, in humans, consumption of fast food was found to be associated with a higher risk of depression (Sánchez-Villegas et al., 2012). Therefore, overweight and obese adolescents who frequently consumed fast foods could also be exposed to the worsening of their psychological well-being. However, there is little information in the literature about the relationship of fast food consumption with a wide range of emotional and behavioural problems especially among the overweight and obese adolescents. Hence, this study aimed to elucidate the association of fast food with emotional and behavioural problem among secondary school adolescents of MyBFF@school intervention program.

\section{Methods}

This was a baseline data of a school-based cluster randomised controlled trial, the 'My Body is Fit and Fabulous at school' (MyBFF@school) intervention study. Trained personnel measured the BMI of 10866 adolescents aged 13, 14 and 16 years old, with no medical condition from fifteen secondary schools to screen for overweight and obese adolescents. The adolescents were categorised as overweight if their BMI-for-age is more than $+1 \mathrm{SD}$ and less than or equal to $+2 \mathrm{SD}$ while adolescents with BMI-for-age exceeding $+2 \mathrm{SD}$ were categorised as obese based on the WHO 2007 Growth Reference ("WHO | BMIfor-age (5-19 years)," n.d.). There were 2910 (26.8\%) adolescents who are either overweight or obese found from the screening process. They were approach for consents from parents or guardian to participate in the study and informed written consents were received from 1041 (35.8\%) adolescents.

Baseline data were collected through a socio-demographic characteristics questionnaire that were answered by their parents. The participating adolescents answered two self-reported questionnaires which were the nutritional knowledge, attitude and practice (KAP) questionnaire as well as the Youth Self-Report questionnaire. Only 619 (\%) adolescents completed both questionnaires and will be considered in the analysis.

This study was conducted according to the guidelines laid down in the Declaration of Helsinki and all procedures involving research study participants were approved by the Medical Research and Ethics Committee (MREC), Ministry of Health Malaysia and Educational Planning and Research Division (EPRD), Ministry of Education Malaysia (ethical code: NMRR-13-439-16563). Written informed consent was obtained from the parents or guardian of all subjects and written informed assent was obtained from all subjects. 


\section{Instrument}

Data on frequency of fast food consumption was collected through the nutritional KAP questionnaire that was developed and pre-tested during the pilot study in Putrajaya in 2015. The adolescents were asked on how many days they eat fast foods for the past seven days. Fast foods in this study refer to foods purchased from fast food restaurants such as burger, pizza, fried chicken and French fries. Meanwhile, the Youth Self-Report (YSR) questionnaire was utilized to measure the symptoms of emotional and behavioural problems among the adolescents (T. M. Achenbach, 1991). The instrument contains 112 Likert-scaled items with eight subscales namely anxious/depressed, withdrawn/depressed, somatic complaints, social problems, thought problems, attention problems, rule-breaking behaviour and aggressive behaviour (T. M. Achenbach, 1991; Thomas M Achenbach \& Rescorla, 2001). The questionnaire was translated from English to Malay through a back-to-back translation. It was then pre-tested and piloted among adolescents in Putrajaya during the pilot study and was found to be reliable with a Cronbach alpha of 0.95 .

\section{Statistical Analysis}

Chi-square test was used to quantify the association between categorical variables. Spearman's rank order correlation was estimated to determine the relationship between fast food consumption and the symptoms of emotional and behavioural problems. The data were stratified based on gender, location and ethnicity in the correlational analyses. All statistical tests were conducted at 5\% significance level. All data analyses were run using IBM Statistical Package for the Social Sciences (SPSS) version 20 (SPSS Inc., Chicago,IL., USA).

\section{Result}

There were 624 adolescents with a mean age(SD) of 14.6(1.3) years old who completed both the nutritional KAP and YSR questionnaire. Gender distribution were found to be statistically significant difference at baseline between the two arms $\left(\mathrm{X}^{2}(1)=8.362\right.$, $\mathrm{p}=0.004)$. The number of girls in this study was greater than the number of boys as shown in Table 1.

Table 1

Demography of participants

\begin{tabular}{lcccc}
\hline $\begin{array}{c}\text { Characteristic of } \\
\text { respondents }\end{array}$ & Overweight & Obese & Chi-square & $p$ value \\
\hline Sex, $\mathrm{n}(\%)$ & & & & \\
$\quad$ Boy & $95(41.3)$ & $135(58.7)$ & $8.362^{*}$ & 0.004 \\
Girl & $210(53.3)$ & $184(46.7)$ & & \\
Age groups, $\mathrm{n}(\%)$ & & & & \\
13 years & $92(49.2)$ & $95(50.8)$ & 0.649 & 0.723 \\
14 years & $73(46.2)$ & $85(53.8)$ & & \\
16 years & $140(50.2)$ & $139(49.8)$ & & \\
Location, $\mathrm{n}(\%)$ & & & \\
Rural & $93(46.0)$ & $109(54.0)$ & 0.963 & 0.326 \\
Urban & $212(50.2)$ & $210(49.8)$ & & \\
Ethnicity, $\mathrm{n}(\%)$ & & & & \\
Malay & $230(47.0)$ & $259(53.0)$ & 3.570 & 0.312 \\
Chinese & $28(56.0)$ & $22(44.0)$ & & \\
Indian & $42(56.8)$ & $32(43.2)$ & & \\
Others & $5(45.5)$ & $6(54.5)$ & & \\
\hline$* p<.01$ & & &
\end{tabular}


Weak but statistically significant positive associations were observed between the frequency of fast food consumption in the past week with the symptoms of; anxious/depressed $\left(\mathrm{r}_{\mathrm{s}}=0.082, \mathrm{p}<0.05\right)$; somatic complaints $\left(\mathrm{r}_{\mathrm{s}}=0.139, \mathrm{p}<0.01\right)$; social problems $\left(\mathrm{r}_{\mathrm{s}}=0.115, \mathrm{p}<0.01\right)$; thought problems $\left(\mathrm{r}_{\mathrm{s}}=0.118, \mathrm{p}<0.01\right)$; attention problems $\left(\mathrm{r}_{\mathrm{s}}=\right.$ $0.125, \mathrm{p}<0.01)$; rule-breaking behaviour $\left(\mathrm{r}_{\mathrm{s}}=0.144, \mathrm{p}<0.001\right)$; and aggressive behaviour $\left(\mathrm{r}_{\mathrm{s}}=\right.$ $0.168, \mathrm{p}<0.001)$ as shown in Table 2.

Table 2

Correlation Between YSR Subscales and Frequency of Fast Food Consumption

\begin{tabular}{lc}
\hline YSR Symptoms & Spearman's rank-order correlation \\
\hline Withdrawn/Depressed & 0.044 \\
Anxious/ Depressed & 0.076 \\
Somatic Complaints & $0.135^{* *}$ \\
Social Problems & $0.109^{* *}$ \\
Thought Problems & $0.114^{* *}$ \\
Attention Problems & $0.123^{* *}$ \\
Rule-breaking Behaviour & $0.139^{* *}$ \\
& \\
Aggressive Behaviour & $0.162^{* *}$ \\
Total Behaviour & $0.135^{* *}$ \\
& \\
\hline
\end{tabular}

${ }^{* *} p<.01$

Differences in associations between fast food consumption and the symptoms of emotional and behavioural problems were observed after stratifying the data based on gender, locality of school and ethnicity of the adolescents. Significant associations were found between fast food consumption among boys and behavioural problems only while fast food consumption among girls have significant associations with all symptoms of emotional and behavioural problems apart from the symptoms of withdrawn/depressed as shown in Table 3.

Table 3

Correlation Between YSR Subscales and Frequency of Fast Food Consumption based on Gender

\begin{tabular}{lcc}
\hline \multirow{2}{*}{ YSR Symptoms } & \multicolumn{2}{c}{ Gender } \\
\cline { 2 - 3 } & Boy & Girl \\
\hline Withdrawn/Depressed & 0.044 & 0.057 \\
Anxious/ Depressed & 0.061 & $0.103^{*}$ \\
Somatic Complaints & 0.106 & $0.158^{* *}$ \\
Social Problems & 0.112 & $0.110^{*}$ \\
Thought Problems & 0.087 & $0.129^{*}$ \\
Attention Problems & 0.089 & $0.155^{* *}$ \\
Rule-breaking Behaviour & $0.134^{*}$ & $0.124^{*}$ \\
Aggressive Behaviour & $0.172^{* *}$ & $0.160^{* *}$ \\
Total Behaviour & 0.122 & $0.152^{* *}$ \\
\hline
\end{tabular}

$* \mathrm{p}<.05 * * \mathrm{p}<.01$ 
Besides that, significant associations of fast food consumption among adolescents from rural schools were not observed with three symptoms namely the symptoms of withdrawn/depressed, attention problems and rule-breaking behaviour. While, fast food consumption among adolescents from urban schools were not observed with the symptoms of withdrawn/depressed, anxious/depressed and social problems as shown in Table 4.

Table 4

Correlation Between YSR Subscales and Frequency of Fast

Food Consumption based on School Location

\begin{tabular}{lcc}
\hline \multirow{2}{*}{ YSR Symptoms } & \multicolumn{2}{c}{ School Location } \\
\cline { 2 - 3 } & Rural & Urban \\
\hline Withdrawn/Depressed & 0.068 & 0.035 \\
Anxious/ Depressed & $0.202^{* *}$ & 0.027 \\
Somatic Complaints & $0.216^{* *}$ & $0.098^{*}$ \\
Social Problems & $0.175^{*}$ & 0.080 \\
Thought Problems & $0.148^{*}$ & $0.100^{*}$ \\
Attention Problems & 0.106 & $0.135^{* *}$ \\
Rule-breaking Behaviour & 0.099 & $0.161^{* *}$ \\
Aggressive Behaviour & $0.196^{* *}$ & $0.153^{* *}$ \\
Total Behaviour & $0.174^{*}$ & $0.127^{*}$ \\
\hline
\end{tabular}

$* \mathrm{p}<.05 * * \mathrm{p}<.01$

Further, significant associations were observed between fast food consumption among adolescents of the Malay ethicity with all symptoms of emotional and behavioural problems apart from the symptom of withdrawn/depressed. Significant associations were also observed among adolescents of the Indian ethnicity in the symptom of aggressive behaviour and among adolescents of the Chinese ethnicity in the symptoms of rule-breaking behaviour, aggressive behaviour and somatic complaints. Meanwhile, there is no significant association observed among adolescents from other ethnicity as shown in Table 5.

Table 5

Correlation Between YSR Subscales and Frequency of Fast Food Consumption based on Ethnicity

\begin{tabular}{lcccc}
\hline \multirow{2}{*}{ YSR Symptoms } & \multicolumn{4}{c}{ Ethnicity } \\
\cline { 2 - 5 } & Malay & Chinese & Indian & Others \\
\hline Withdrawn/Depressed & 0.009 & 0.115 & 0.063 & 0.348 \\
Anxious/ Depressed & $0.091^{*}$ & -0.124 & 0.113 & -0.081 \\
Somatic Complaints & $0.098^{*}$ & $0.436^{* *}$ & 0.164 & 0.303 \\
Social Problems & $0.100^{*}$ & 0.083 & 0.120 & 0.010 \\
Thought Problems & $0.106^{*}$ & 0.080 & 0.146 & 0.283 \\
Attention Problems & $0.091^{*}$ & 0.261 & 0.175 & 0.113 \\
Rule-breaking Behaviour & $0.118^{*}$ & $0.287^{*}$ & $0.296^{*}$ & -0.287 \\
Aggressive Behaviour & $0.136^{* *}$ & $0.393^{* *}$ & 0.208 & -0.275 \\
Total Behaviour & $0.117^{*}$ & 0.276 & 0.134 & -0.014 \\
\hline
\end{tabular}

$* \mathrm{p}<.05 * * \mathrm{p}<.01$ 


\section{Discussion}

The positive associations between the frequency of fast food consumption with the symptoms of emotional and behavioural problems imply that higher frequency of fast food consumption is associated with worse emotional and behavioural problems among the overweight and obese adolescents. We hypothesise that the relationships between them may exist mainly due to the mechanism of the gut-brain axis. Changes in the species of microbiome that resides in our gastrointestinal tract can influence stress-related behaviour (Foster \& McVey Neufeld, 2013). The microbiota are responsible in the regulation of hypothalamic-pituitary-adrenal (HPA) axis at early age as well as in the reaction of our body towards stress throughout our life (Foster \& McVey Neufeld, 2013). The HPA axis plays a role in modulating stress and changes in its activity have been associated with depression (Belvederi Murri et al., 2014; Wasserman, Wasserman, \& Sokolowski, 2010). Changes in our diet can influence the gut microbiota composition which could eventually influence stressrelated behaviour (Flint, Duncan, Scott, \& Louis, 2015). Evidences from research on mice have shown that high-fat diet can increase anxious and depressive behaviours (Luna \& Foster, 2015). While, research on humans has discovered a correlation between fecal mirobiota and depression (Naseribafrouei et al., 2014). These evidences coincide with the significant association between fast food and the symptoms of anxious/depressed among the obese and overweight adolescents found in this study.

Even though the cause of somatic symptoms is medically unexplainable, they are often regarded as the effects of stress as well as other factors such as biological and interpersonal factors (Mayou \& Farmer, 2002). An experimental study discovered that stressed emotional eaters would usually consume energy-densed foods that are high in sugar, salts and fats as these types of food could alleviate their mood due to the release of dopamine in their brain (Horsch et al., 2015; Leigh Gibson, 2006; Oliver, Wardle, \& Gibson, 2000). Thus, fast foods might be one of their best options when they were stressed since these foods typically contains high sodium, sugar, total fat and trans-fat (Dunford, Webster, Barzi, \& Neal, 2010; Stender et al., 2006). Therefore, stress could be the potential mediator of frequent consumption of fast foods and the prevalence of somatic symptoms which are in accordance with the result of our study.

A range of emotional and behavioural problems such as social problems, thought problems, attention problems, rule-breaking behaviour and aggressive behaviour faced by the overweight and obese adolescents in this study may be related to the development of manialike behaviour and hyperactive behaviour due to the trans-fat in the fast foods consumed by the adolescents. A study on rats found that their brain cortex would assimilate trans-fat under prolonged consumption which would eventually leads to mania-like behaviour that includes hyperactive behaviour (Trevizol et al., 2015). The development of these behaviours is expected to be due to the declining level of brain-derived neurotrophic factor (BDNF) as there is a correlation between the level of BDNF with the development of bipolar disorder (Cunha et al., 2006; Trevizol et al., 2015). Mania-like behaviour could worsen interpersonal relationship due to impairment of facial emotion which would cause social problems (Lembke $\&$ Ketter, 2002). The inability to accurately determine facial emotion is also associated with thought problems (Wickline, Nowicki, Bollini, \& Walker, 2012). Amid, hyperactivity behaviour is characterised by restless, inattentive and impulsive behaviour that could lead to attention problems, aggressive behaviour as well as social problems such as peer rejection (Schachar, 1991; Spira \& Fischel, 2005). On top of that, it also has a strong link with rulebreaking behaviour (McArdle, O’Brien, \& Kolvin, 1995).

The high fat and salt content in fast food may cause it to become potentially addictive (K. Garber \& H. Lustig, 2011). The amount of sugar in soda that often comes with fast foods is usually ten times the normal amount which can cause the release of excessive dopamine in the brain (Avena, Rada, \& Hoebel, 2009; K. Garber \& H. Lustig, 2011). The effect is similar to that of drug abuse where addictive-like behaviour would likely to occur (Avena et al., 2009). To make it worse, obese children usually have resistance to hormones that control appetite and limit reward compared to children with normal body weight who have no 
problem in receiving normal hunger and satiety signals (K. Garber \& H. Lustig, 2011; Mietus-Snyder \& Lustig, 2008). Thus, it would be harder for obese individuals to reduce their weight especially when they are addicted to fast foods. Children who are not satisfied with their body image are likely to perpetrate bullying (Rech, Halpern, Tedesco, \& Santos, 2013). This could exacerbate social problems, aggressive behaviour and rule-breaking behaviour. Studies have found that the two most-preferred fast foods by Malaysian adolescents contain a very high amount of trans-fat (how much?) which could cause them to be hyperactive under prolonged consumption (Habib, Abu Dardak, \& Zakaria, 2011; Stender et al., 2006; Trevizol et al., 2015).

The differences in gender observed in this study could be due to the different hormonal mechanism between the gender since there is an association between aggressive behaviour with testosterone, the main androgernic hormone (de Almeida, Cabral, \& Narvaes, 2015). Our finding is also consistent with a study among early adolescent boys aged 6 to 13 years old that revealed boys with higher body mass are more likely to exhibit aggressive behaviour (Tremblay, 1998). Another study among Singaporean adolescents found significantly greater emotional distress among girls than among boys (Yeo, Ang, Chong, \& Huan, 2007). Further, a study by Brooks et al. revealed that girls could reduce the odds of depression by eating healthy diet (Brooks, Harris, Thrall, \& Woods, 2002).

Differences in locality of school could be attributed to several factors. A study by Miles, Coutts and Mohamadi found that neighbourhood urban form and social environment in Miami could affect the level of depression among the residents (Miles, Coutts, \& Mohamadi, 2012). Another study revealed the difference in social context between urban and rural children which could explain the difference in association of social problems with fast food consumption based on the locality of school (Chen, Wang, \& Wang, 2009). Adolescents from urban and rural school also faced stresses that are qualitatively different due to their socioeconomic status (Elgar, Arlett, \& Groves, 2003).

Differences in ethnicity found in this study could be due to sociocultural influence on body dissatisfaction which is associated with stress level (Mellor et al., 2009; Murray, Rieger, \& Byrne, 2015). Adolescents of different ethnicity in Malaysia were exposed to different perceived pressure from adults, siblings and friends to reduce their weight (Mellor et al., 2009). The same study found that these pressures are predictors of body dissatisfaction among Chinese girls and adolescents of the Malay ethnicity which could concurrently lead to elevated stress level (Mellor et al., 2009; Murray et al., 2015).

\section{Limitations of This Study}

A limitation of this study is the possibility of recall bias that occur when the adolescents were asked on how many days they eat fast foods in the past seven days. The adolescents might not remember the past events in details as to them giving an accurate report. Another limitation is the usage of the YSR to deduce the symptoms of emotional and behavioural problems faced by the adolescents which is mediated with high internal consistency. Further, comparison with adolescents who have normal body weight cannot be made due their exclusion from this study.

\section{Conclusion}

Fast food consumption significantly associated with a range of emotional and behavioural problems which include the symptoms of anxious/depressed, somatic complaints, social problems, thought problems, attention problems, rule-breaking behaviour and aggressive behaviour among overweight and obese adolescents. There were differences in the associations based on gender, locality of schools and ethnicity. Therefore, WHO guidelines on fast food consumption should be adhered strictly by discouraging its consumption especially among overweight and obese adolescents. Hence, nutrition education is of paramount importance to the overweight and obese adolescents, primarily in the topics related to appetite control, the addictive nature of fast food and the health effects that it would bring 
to them. Interventions to reduce emotional and behavioural problems could also aim at reduction in fast food consumption to mediate the problems.

\section{Acknowledgements}

The authors would like to thank the Director General of Health Malaysia for his permission to publish this article, the Ministry of Education for giving the approval for us to undertake this study, all researchers, staff of Ministry of Health, participants and teachers for helping in data collection. Special thanks to Dr. Hj. Tahir Bin Aris as the coordinator of MyBFF@school project.

\section{Declaration of Conflicting Interests}

The authors declare that there is no conflict of interest.

\section{Funding}

The author(s) disclosed receipt of the following financial support for the research, authorship, and/or publication of this article: This work was supported by the Ministry of Health Malaysia [grant number NMRR-13-439-16563].

\section{Ethical standards disclosure}

This study was conducted according to the guidelines laid down in the Declaration of Helsinki and all procedures involving research study participants were approved by the Medical Research and Ethics Committee (MREC), Ministry of Health Malaysia and Educational Planning and Research Division (EPRD), Ministry of Education Malaysia (ethical code: NMRR-13-439-16563). Written informed consent was obtained from the parents or guardian of all subjects and written informed assent was obtained from all subjects.

\section{References}

Achenbach, T. M. (1991). Manual for the Youth Self-Report and 1991 Profile. Department of Psychiatry, University of Vermont.

Achenbach, Thomas M, \& Rescorla, L. A. (2001). Manual for the ASEBA School-Age Forms \& Profiles. University of Vermont, Research Centre for Children, Youth \& Families: Burlington, VT.

Avena, N. M., Rada, P., \& Hoebel, B. G. (2009). Sugar and Fat Bingeing Have Notable Differences in Addictive-like Behavior. The Journal of Nutrition, 139(3), 623-628. https://doi.org/10.3945/jn.108.097584

Belvederi Murri, M., Pariante, C., Mondelli, V., Masotti, M., Atti, A. R., Mellacqua, Z., ... Amore, M. (2014). HPA axis and aging in depression: Systematic review and metaanalysis. Psychoneuroendocrinology, 41, 46-62. https://doi.org/10.1016/j.psyneuen.2013.12.004

Brooks, T. L., Harris, S. K., Thrall, J. S., \& Woods, E. R. (2002). Association of adolescent risk behaviors with mental health symptoms in high school students. Journal of Adolescent Health, 31(3), 240-246. https://doi.org/10.1016/S1054-139X(02)00385-3

Brouwer, I. A., Wanders, A. J., \& Katan, M. B. (2010). Effect of Animal and Industrial Trans Fatty Acids on HDL and LDL Cholesterol Levels in Humans - A Quantitative Review. PLOS ONE, 5(3), e9434. https://doi.org/10.1371/journal.pone.0009434

Carabotti, M., Scirocco, A., Maselli, M. A., \& Severi, C. (2015). The gut-brain axis: interactions between enteric microbiota, central and enteric nervous systems. Annals of Gastroenterology: Quarterly Publication of the Hellenic Society of Gastroenterology, 28(2), 203-209. 
Chen, X., Wang, L., \& Wang, Z. (2009). Shyness-Sensitivity and Social, School, and Psychological Adjustment in Rural Migrant and Urban Children in China. Child Development, 80(5), 1499-1513. https://doi.org/10.1111/j.1467-8624.2009.01347.x

Cunha, A. B. M., Frey, B. N., Andreazza, A. C., Goi, J. D., Rosa, A. R., Gonçalves, C. A., ... Kapczinski, F. (2006). Serum brain-derived neurotrophic factor is decreased in bipolar disorder during depressive and manic episodes. Neuroscience Letters, 398(3), 215-219. https://doi.org/10.1016/j.neulet.2005.12.085

de Almeida, R. M. M., Cabral, J. C. C., \& Narvaes, R. (2015). Behavioural, hormonal and neurobiological mechanisms of aggressive behaviour in human and nonhuman primates. Physiology \& Behavior, 143, 121-135. https://doi.org/10.1016/j.physbeh.2015.02.053

Dunford, E., Webster, J., Barzi, F., \& Neal, B. (2010). Nutrient content of products served by leading Australian fast food chains. Appetite, 55(3), 484-489. https://doi.org/10.1016/j.appet.2010.08.015

Elgar, F. J., Arlett, C., \& Groves, R. (2003). Stress, coping, and behavioural problems among rural and urban adolescents. Journal of Adolescence, 26(5), 574-585. https://doi.org/10.1016/S0140-1971(03)00057-5

Flint, H. J., Duncan, S. H., Scott, K. P., \& Louis, P. (2015). Links between diet, gut microbiota composition and gut metabolism. Proceedings of the Nutrition Society, 74(1), 13-22. https://doi.org/10.1017/S0029665114001463

Foster, J. A., \& McVey Neufeld, K.-A. (2013). Gut-brain axis: how the microbiome influences anxiety and depression. Trends in Neurosciences, 36(5), 305-312. https://doi.org/10.1016/j.tins.2013.01.005

Habib, F. Q., Abu Dardak, R., \& Zakaria, S. (2011). Consumers' preference and consumption towards fast food: evidences from Malaysia / Farzana Quoquab Habib , Rozhan Abu Dardak, Sabarudin Zakaria. Business \& Management Quaterly Review, 2, 14-27.

Healthy diet. (n.d.). Retrieved December 10, 2018, from https://www.who.int/newsroom/fact-sheets/detail/healthy-diet

Horsch, A., Wobmann, M., Kriemler, S., Munsch, S., Borloz, S., Balz, A., ... Puder, J. J. (2015). Impact of physical activity on energy balance, food intake and choice in normal weight and obese children in the setting of acute social stress: a randomized controlled trial. BMC Pediatrics, 15(1), 12. https://doi.org/10.1186/s12887-015-03267

K. Garber, A., \& H. Lustig, R. (2011). Is Fast Food Addictive? Current Drug Abuse Reviews, $4(3), 146-162$.

Leigh Gibson, E. (2006). Emotional influences on food choice: Sensory, physiological and psychological pathways. Physiology \& Behavior, 89(1), 53-61. https://doi.org/10.1016/j.physbeh.2006.01.024

Lembke, A., \& Ketter, T. A. (2002). Impaired Recognition of Facial Emotion in Mania. American Journal of Psychiatry, 159(2), 302-304. https://doi.org/10.1176/appi.ajp.159.2.302

Luna, R. A., \& Foster, J. A. (2015). Gut brain axis: diet microbiota interactions and implications for modulation of anxiety and depression. Current Opinion in Biotechnology, 32, 35-41. https://doi.org/10.1016/j.copbio.2014.10.007

Mayou, R., \& Farmer, A. (2002). Functional somatic symptoms and syndromes. BMJ : British Medical Journal, 325(7358), 265-268.

McArdle, P., O’Brien, G., \& Kolvin, I. (1995). Hyperactivity: Prevalence and Relationship with Conduct Disorder. Journal of Child Psychology and Psychiatry, 36(2), 279-303. https://doi.org/10.1111/j.1469-7610.1995.tb01825.x

Mellor, D., McCabe, M., Ricciardelli, L., Yeow, J., Daliza, N., \& Hapidzal, N. F. bt M. (2009). Sociocultural influences on body dissatisfaction and body change behaviors among Malaysian adolescents. Body Image, 6(2), 121-128. https://doi.org/10.1016/j.bodyim.2008.11.003 
Mietus-Snyder, M. L., \& Lustig, R. H. (2008). Childhood obesity: adrift in the "limbic triangle." Annual Review of Medicine, 59, 147-162. https://doi.org/10.1146/annurev.med.59.103106.105628

Miles, R., Coutts, C., \& Mohamadi, A. (2012). Neighborhood Urban Form, Social Environment, and Depression. Journal of Urban Health, 89(1), 1-18. https://doi.org/10.1007/s11524-011-9621-2

Mozaffarian, D., Katan, M. B., Ascherio, A., Stampfer, M. J., \& Willett, W. C. (2006). Trans Fatty Acids and Cardiovascular Disease. New England Journal of Medicine, 354(15), 1601-1613. https://doi.org/10.1056/NEJMra054035

Murray, K., Rieger, E., \& Byrne, D. (2015). The relationship between stress and body satisfaction in female and male adolescents. Stress and Health: Journal of the International Society for the Investigation of Stress, 31(1), 13-23. https://doi.org/10.1002/smi.2516

Naseribafrouei, A., Hestad, K., Avershina, E., Sekelja, M., Linløkken, A., Wilson, R., \& Rudi, K. (2014). Correlation between the human fecal microbiota and depression. Neurogastroenterology \& Motility, 26(8), 1155-1162. https://doi.org/10.1111/nmo.12378

Nederkoorn, C., Braet, C., Van Eijs, Y., Tanghe, A., \& Jansen, A. (2006). Why obese children cannot resist food: The role of impulsivity. Eating Behaviors, 7(4), 315-322. https://doi.org/10.1016/j.eatbeh.2005.11.005

Oliver, G., Wardle, J., \& Gibson, E. L. (2000). Stress and Food Choice: A Laboratory Study. Psychosomatic Medicine, 62(6), 853.

Poti, J. M., \& Popkin, B. M. (2011). Trends in energy intake among US children by eating location and food source, 1977-2006. Journal of the American Dietetic Association, 111(8), 1156-1164. https://doi.org/10.1016/j.jada.2011.05.007

Rech, R. R., Halpern, R., Tedesco, A., \& Santos, D. F. (2013). Prevalence and characteristics of victims and perpetrators of bullying. Jornal de Pediatria, 89(2), 164-170. https://doi.org/10.1016/j.jped.2013.03.006

Sánchez-Villegas, A., Toledo, E., Irala, J. de, Ruiz-Canela, M., Pla-Vidal, J., \& MartínezGonzález, M. A. (2012). Fast-food and commercial baked goods consumption and the risk of depression. Public Health Nutrition, 15(3), 424-432. https://doi.org/10.1017/S1368980011001856

Schachar, R. (1991). Childhood Hyperactivity. Journal of Child Psychology and Psychiatry, 32(1), 155-191. https://doi.org/10.1111/j.1469-7610.1991.tb00007.x

Spira, E. G., \& Fischel, J. E. (2005). The impact of preschool inattention, hyperactivity, and impulsivity on social and academic development: a review. Journal of Child Psychology and Psychiatry, 46(7), 755-773. https://doi.org/10.1111/j.14697610.2005.01466.x

Stender, S., Dyerberg, J., \& Astrup, A. (2006). High Levels of Industrially Produced Trans Fat in Popular Fast Foods. New England Journal of Medicine, 354, 1650-1652. https://doi.org/10.1056/nejmc052959

Surveys, N. R. C. (US) C. C. on E. of F. C. (1984). The Nationwide Food Consumption Surveys. Retrieved from https://www.ncbi.nlm.nih.gov/books/NBK217707/

Tremblay, R. E. (1998). Testosterone, Physical Aggression, Dominance, and Physical Development in Early Adolescence. International Journal of Behavioral Development, 22(4), 753-777. https://doi.org/10.1080/016502598384153

Trevizol, F., Roversi, Kr., Dias, V. T., Roversi, K., Barcelos, R. C. S., Kuhn, F. T., ... Bürger, M. E. (2015). Cross-generational trans fat intake facilitates mania-like behavior: Oxidative and molecular markers in brain cortex. Neuroscience, 286, 353-363. https://doi.org/10.1016/j.neuroscience.2014.11.059

U.S. Department of Agriculture ARS BHNRC, Food Surveys Research Group. (n.d.). Dietary Intake Data. What we eat in America. NHANES 2005-2006. Retrieved from http://www.ars.usda.gov/ba/bhnrc/fsrg 
Wasserman, D., Wasserman, J., \& Sokolowski, M. (2010). Genetics of HPA-axis, depression and suicidality. European Psychiatry, 25(5), 278-280. https://doi.org/10.1016/j.eurpsy.2009.12.016

WHO | BMI-for-age (5-19 years). (n.d.). Retrieved May 17, 2018, from World Health Organization website: http://www.who.int/growthref/who2007_bmi_for_age/en/

Wickline, V. B., Nowicki, S., Bollini, A. M., \& Walker, E. F. (2012). Vocal and Facial Emotion Decoding Difficulties Relating to Social and Thought Problems: Highlighting Schizotypal Personality Disorder. Journal of Nonverbal Behavior, 36(1), 59-77. https://doi.org/10.1007/s10919-011-0125-2

Yeo, L. S., Ang, R. P., Chong, W. H., \& Huan, V. S. (2007). Gender differences in adolescent concerns and emotional well-being: perceptions of Singaporean adolescent students. The Journal of Genetic Psychology, 168(1), 63-80. https://doi.org/10.3200/GNTP.168.1.63-80

Zhao, Y., Wang, L., Xue, H., Wang, H., \& Wang, Y. (2017). Fast food consumption and its associations with obesity and hypertension among children: results from the baseline data of the Childhood Obesity Study in China Mega-cities. BMC Public Health, 17. https://doi.org/10.1186/s12889-017-4952-x 